\title{
Preoperative Assessment and Management of Patients with Pain and Anxiety Disorders
}

\author{
Lisa V. Doan ${ }^{1}$ • Jeanna Blitz ${ }^{2}$ \\ Published online: 10 January 2020 \\ (C) Springer Science+Business Media, LLC, part of Springer Nature 2020
}

\begin{abstract}
Purpose of Review This review summarizes selected recent evidence on issues important for preoperative pain evaluation. Recent Findings Opioids, though a mainstay of postoperative pain management, are associated with both short and increasingly recognized long-term risks, including persistent opioid use. Risk factors for high levels of acute postoperative pain as well as chronic postsurgical pain may overlap, including psychological factors such as depression, anxiety, and catastrophizing. Tools to predict those at risk for poor postoperative pain outcomes are being studied.

Summary Preoperative pain and psychological factors can affect postoperative pain outcomes. More work is needed in the future to develop practical interventions in the preoperative period to address these factors.
\end{abstract}

Keywords Opioids $\cdot$ Catastrophizing $\cdot$ Anxiety $\cdot$ Postoperative pain

\section{Introduction}

There is increasing evidence of the connection between psychological interventions and improvement in the postoperative pain experience [1]. Preparing for surgery is a momentous time in a patient's life, commonly marked by confusion and anxiety. Feelings of despair and being overwhelmed by the process are heightened for patients with preexisting anxiety, chronic pain conditions, or high levels of catastrophization. Furthermore, patients with anxiety or other mental health conditions may avoid health care due to fear of stigmatization or prior negative experiences with health-care providers. They may enter the perioperative space with unidentified or poorly managed comorbid conditions. Concomitant substance use disorders or social isolation may further hinder perioperative optimization initiatives and outcomes. All of these factors may result in avoidable postoperative complications and increase in length of hospitalization and

This article is part of the Topical Collection on Preoperative Evaluation.

Jeanna Blitz

Jeanna.blitz@duke.edu

1 Department of Anesthesiology, Perioperative Care and Pain Medicine, New York University School of Medicine, New York, NY, USA

2 Department of Anesthesiology, Duke University School of Medicine, Durham, NC, USA readmissions if not addressed. Specifically, poorly controlled postoperative pain may delay recovery, prolong hospitalization, decrease patient satisfaction with their care, and ultimately result in a chronic pain condition [2].

One benefit of a comprehensive preoperative evaluation clinic is the opportunity to implement population health initiatives [3] through the integration of programs that fulfill the triple aim: improve the experience of care, improve the health of populations, and reduce per capita costs [4]. For many patients, the preoperative period represents a unique window of time when they may be most receptive to making lifestyle and behavioral modifications than at other times in their lives. Capitalizing on this "teachable moment" to improve the patient's surgical preparedness as well as his/her long-term health outcomes is the basis of prehabilitation. Prehabilitation extends beyond physical preparation, to include psychological preparedness as well [5]. Using the preoperative evaluation visit to enact preoperative optimization strategies such as teaching new ways to cope with stress, managing perioperative expectations, and introducing mindfulness techniques has significant potential to improve health well beyond the postoperative period. Perioperative pain and its safe management are key concerns, especially in the era of the opioid epidemic. Comprehensive pain management strategies that start in the preoperative period are needed to optimize pain management in the acute postoperative period and to reduce risks for chronic postsurgical pain and persistent opioid use (Table 1). 
Table 1 Perioperative Risks

\begin{tabular}{lll}
\hline & Opioid Related & Pain Related \\
\hline Short term & $\bullet$ Opioid-related adverse drug events & $\bullet$ High levels of postoperative pain \\
& $\bullet$ Increased morbidity in opioid dependent patients & \\
Long term & $\bullet$ Persistent opioid use & $\bullet$ Chronic postsurgical pain \\
\hline
\end{tabular}

\section{Perioperative Risks}

\section{Risks Related to Opioid Use}

Opioids remain a mainstay of acute, postoperative pain management. However, opioid-related adverse drug events (ORADE) are common and include nausea, vomiting, constipation, pruritus, sedation, and respiratory depression. The incidence of ORADE is 9.1 to $11.5 \%$ in retrospective studies of adults undergoing surgical procedures [6-8]. The most common ORADE were respiratory, gastrointestinal, urinary, and central nervous system in nature. ORADE are associated with other poor outcomes as well. In analyses adjusting for confounders, those who experienced ORADE had significantly greater odds of prolonged length of stay, higher hospitalization costs, and mortality [7, 8]. In a study of opioid naïve patients presenting for noncardiac surgery, independent risk factors for ORADE included older age, male sex, and increased comorbidity as measured by Elixhauser Comorbidity Score and Medicare Severity Diagnosis Related Group (MS-DRG) weight [8].

Some patients presenting for surgery are already taking opioids, and there is growing evidence of the association between preoperative opioid use and poor postoperative outcomes. The prevalence of preoperative opioid use ranges from 8.8 to $35 \%$, with higher rates in certain groups such as orthopedic populations [9-14]. In a large cohort study of patients who underwent elective abdominal surgery, preoperative use of opioids was associated with longer hospital stays, greater rates of readmission, and increased expenditures, adjusting for confounders [12]. Similarly, associations between preoperative opioid use and longer hospital stays and higher readmission rates have been found in general, vascular, and orthopedic populations [15-18]. Preoperative opioid use has been associated with increased postoperative morbidity, including infection, respiratory failure, and cardiac events [10, 13, 16].

Finally, opioid dependence and addiction are a public health crisis. A key exposure is prescription of opioids for postoperative pain management. Persistent opioid use is increasingly recognized as a risk of surgery. In a cohort study of patients undergoing minor and major surgeries, the incidence of new persistent opioid use, defined as opioid prescription between 90 and 180 days postoperatively, was similar between the two groups, ranging from 5.9 to $6.5 \%$. The incidence in the nonoperative cohort was $0.4 \%$ [19]. Independent risk factors for persistent opioid use in this cohort were tobacco use, alcohol and substance use disorders, anxiety, depression, and presence of preoperative pain conditions. In a different retrospective cohort study of 11 types of surgical procedures, defining persistent opioid use as having filled 10 or more prescriptions or greater than 120 days' supply 3 months to 1 year postoperatively, the incidence of chronic opioid use ranged from 0.119 for cesarean section to $1.41 \%$ for total knee replacement [20•]. Independent risk factors for persistent opioid use in this cohort were male sex, age over 50 years, preoperative use of benzodiazepines or antidepressants, depression, and alcohol or substance use disorders.

\section{Pain}

Prior to surgery, postoperative pain is one of the most common concerns for patients. In a US national survey of patients who had undergone surgery in the 5 years prior to survey date, $65 \%$ of respondents rated postoperative pain as moderate, severe, or extreme. Post-discharge, $62 \%$ of respondents reported continued moderate, severe, or extreme pain [21]. Certain surgical procedures are associated with high pain levels. In a prospective study of surgical patients in German hospitals, surgeries with the highest pain levels included major spinal surgeries as well as orthopedic or trauma surgeries on extremities [22]. There are other risk factors for experiencing high levels of postoperative pain besides surgical-related factors. In the aforementioned German study, after adjusting for surgery type, risk factors for severe postoperative pain were preoperative chronic pain, younger age, and female sex [23]. Other studies have been supportive of these findings [24-26]. Preoperative opioid use and dependence has also been found to be associated with greater postoperative pain levels and increased opioid requirements [10, 27-29]. Preoperative psychological factors such as catastrophizing, depression, anxiety, and expectation of pain are also important predictors of high postoperative acute pain intensity [30-33].

Chronic postsurgical pain (CPSP) is a risk of surgery. In studies of mixed surgical populations, the incidence of CPSP was 11.8 to $14.8 \%$ at 1 year or greater $[34,35]$. The incidence is much higher for particular types of surgery, such as amputation, thoracotomy, and breast surgery [36]. Surgical factors play a role, and more studies are needed on genetic factors [36, 37]. Other risk factors for the development of chronic pain include presence of preoperative pain and high levels of acute postoperative pain $[26,36,38]$. Psychological risk factors for CPSP include anxiety, depression, and catastrophizing [38-40]. 


\section{Risks Related to Psychological Disorders}

Psychological factors such as depression and anxiety can increase risk for high levels of postoperative pain, prolonged opioid use, and CPSP. They may also be associated with other poor postoperative outcomes. In a study of total lower extremity joint arthroplasty, a preoperative diagnosis of anxiety or depression was associated with greater odds of postoperative morbidity and increased costs [41]. In a study of patients undergoing major spine surgery, depression and anxiety were associated with increased odds of non-home discharge. Depression, but not anxiety, was associated with increased odds of postoperative complications [42]. In both of these studies, the prevalence of depression and anxiety increased over time [41, 42].

\section{Preoperative Evaluation}

The patient's self-assessment of their preoperative psychological state provides important information about whether or not the patient is at high risk for poor postoperative pain control or dissatisfaction with their overall hospital experience [43]. Furthermore, high levels of depression or anxiety may portend less successful rehabilitation and a slower return to baseline function/recovery [5]. Several tools have been validated for use in the preoperative period. In high-risk patients, including those with opioid use disorder, poorly controlled anxiety, and/ or psychiatric conditions, several preoperative assessment tools may be combined in order to attain a global preoperative risk assessment and individualized preoperative optimization plan. The most commonly used screening tool to detect preoperative anxiety is the Hospital Anxiety and Depression Scale (HADS) scale (Table 2) [43, 44]. This 13-question screening tool aims to identify patients who will benefit most from non-pharmacologic preoperative anxiety reduction strategies such as mindfulness and cognitive behavioral therapy. The Pain Catastrophizing Scale has been well validated in the perioperative period to identify patients as highest risk of poor pain control in the acute postoperative period [45]. It has recently been validated for daily use in surgical patients [46]. Clinical tools to predict risk of postoperative opioid use disorder are evolving but typically include screening for factors such as smoking and substance use status, young age, history of childhood sexual abuse, and lack of social support [47, 48].

Predictive models have been developed to forecast high levels of acute postoperative pain, incorporating questionnaires such as those listed above [49]. Clinical tools to assess preoperative psychological state may not be commonplace in routine practice. Machine learning algorithms have been developed using readily available data from electronic medical records to predict those at risk of high acute postoperative pain with accuracy comparable to models using datasets designed for research [50]. Future work needs to be done to validate and refine these models.

A meta-analysis showed that psychological preparation for surgery, including interventions such as procedural information, cognitive techniques, and relaxation techniques, may be beneficial for postoperative pain outcomes [51]. However, given the heterogeneity of past studies, the overall level of current evidence is considered low [51]. Some of the most promising evidence comes from studies of cognitive behavioral therapy (CBT) and mindfulness-based interventions. For example, in a study of patients undergoing lumbar fusion surgery, preoperative CBT decreased analgesic use in the CBT group [52]. In a small study of patients undergoing lumbar spine surgery, mindfulness-based stress reduction (MBSR) was associated with less back pain at 1 month [53]. However, further study is needed on the potential impact of a preoperative psychological optimization program that includes interventions such as mindfulness and CBT. Psychological prehabilitation programs such as CBT require access to a licensed clinical social worker (LCSW) or other clinicians skilled in the administration of such techniques-a service that few preoperative evaluation clinics in the USA provide at present —outside of major academic medical centers. One feasible approach may be to consolidate CBT services for preoperative smoking cessation initiatives with those for preoperative anxiety and pain reduction programs - a system by which the preoperative evaluation clinic serves as the integrator of optimization services as well as the referral source [54]. Another barrier to the implementation of CBT interventions in the preoperative preparation process is the need for a 6-8-week window of time before surgery in order to implement the full CBT program. Emerging models to predict at-risk patients continue to be developed and may be leveraged during the preoperative assessment [55].

\section{Preoperative Medication Management}

\section{Preoperative Opioids}

Preoperative opioid use may be associated with increased postoperative morbidity, high postoperative pain levels, and increased opioid use. Traditionally goals for perioperative pain management for those on chronic opioids have been avoidance of withdrawal and multimodal strategies to manage pain. More recently, preoperative opioid reduction has been suggested as a strategy to improve postoperative pain outcomes [56••]. Evidence for this strategy is limited. In a retrospective matched cohort study of patients who underwent total joint arthroplasty, chronic opioid users who reduced opioids by at least $50 \%$ preoperatively had improved functional outcome scores compared to those who did not [57]. More evidence is needed to evaluate the impact of this logical strategy. 
Table 2 The Hospital Anxiety and Depression Scale (modified from Zigmond and Snaith. The Depression Scale. Acta psychiatr. Scand. 1983:67:361-370, with permission from John Wiley \& Sons, Inc.)

I feel tense or 'wound up':

$\begin{array}{ll}3 & \text { Most of the time } \\ 2 & \text { A lot of the time } \\ 1 & \text { From time to time } \\ 0 & \text { Not at all } \\ \text { I still enjoy the things I used to enjoy: } \\ 0 & \text { Definitely as much } \\ 1 & \text { Not quite so much } \\ 2 & \text { Only a little } \\ 3 & \text { Hardly at all }\end{array}$

I get a sort of frightened feeling as if something awful is about to happen:

$$
3 \text { Definitely and quite badly }
$$

$2 \quad$ Yes, but not too badly

1 A little, but it does not worry me

$0 \quad$ Not at all

I can laugh and see the funny side of things:

$0 \quad$ As much as I always could

$1 \quad$ Not quite so much now

2 Definitely not so much now

$3 \quad$ Not at all

Worrying thoughts go through my mind:

$\begin{array}{ll}3 & \text { A great deal of the time } \\ 2 & \text { A lot of the time } \\ 1 & \text { From time to time } \\ 0 & \text { Only occasionally } \\ \text { I feel cheerful: } & \\ 0 & \text { Not at all } \\ 1 & \text { Not often } \\ 2 & \text { Sometimes } \\ 3 & \text { Most of the time } \\ \text { I can sit at ease and feel relaxed: } \\ 3 & \text { Definitely } \\ 2 & \text { Usually } \\ 1 & \text { Not often } \\ 0 & \text { Not at all }\end{array}$

I feel as if I am slowed down:

$\begin{array}{ll}0 & \text { Nearly all the time } \\ 1 & \text { Very often } \\ 2 & \text { Sometimes } \\ 3 & \text { Not at all }\end{array}$

I get a sort of frightened feeling like 'butterflies' in the stomach:

$\begin{array}{ll}3 & \text { Not at all } \\ 2 & \text { Occasionally } \\ 1 & \text { Quite often } \\ 0 & \text { Very often }\end{array}$

I have lost interest in my appearance:

$\begin{array}{ll}0 & \text { Definitely } \\ 1 & \text { I do not take quite as much care }\end{array}$

Table 2 (continued)

\begin{tabular}{lc}
\hline 2 & I might not take quite as much care \\
3 & I take just as much care as ever \\
I feel restless as if I have to be on the move: \\
3 & Very much \\
2 & Quite a lot \\
1 & Not very much \\
0 & Not at all \\
I look forward with enjoyment to things: \\
0 & As much as ever \\
1 & Less than I used to \\
2 & Definitely less than I used to \\
3 & Hardly at all \\
I get sudden feelings of panic: \\
3 & Very often indeed \\
2 & Quite often \\
1 & Not very often \\
0 & Not at all \\
I can enjoy a good book or radio or TV program: \\
0 & Often \\
1 & Sometimes \\
2 & Not often \\
3 & Very Seldom \\
\hline
\end{tabular}

Score: 0-7: Low Risk

Score: 8-11: Borderline

Score 11-21: High Risk for Anxiety or Depression

\section{Medication-Assisted Treatment for Opioid Use Disorder}

Methadone, naltrexone, and buprenorphine are medications used to treat opioid use disorder (OUD). Methadone is a $\mu$ opioid agonist with N-methyl-d-aspartate (NMDA) receptor antagonist activity. Methadone for OUD is administered once daily. Preoperatively, the dose should be verified with the opioid treatment program, and maintenance methadone should be continued throughout the perioperative period $[58,56 \bullet \bullet$.

Naltrexone is an opioid antagonist. For OUD it can be administered orally once daily; alternatively, an extended release form is administered intramuscularly once a month. Literature on naltrexone management consists primarily of case reports $[59,60]$. Perioperative management of naltrexone should be coordinated with the naltrexone prescriber. For oral naltrexone, stopping $72 \mathrm{~h}$ before surgery can be considered. For the extended-release injectable form, surgery 4 weeks after the last dose is an option. ${ }^{34}$ Altered opioid sensitivity can be expected. Patients continuing naltrexone will likely require higher doses of opioids. For patients who have stopped, increased sensitivity to opioids may occur due to opioid receptor upregulation.

Buprenorphine is a partial $\mu$ opioid agonist with high affinity. Limited evidence exists to guide perioperative management of buprenorphine. There are contradictory recommendations for perioperative management, with some suggesting stopping buprenorphine and others suggesting continuation 
$[61,62,63 \bullet \cdot, 64]$. The most recently published advisory recommended continuation of buprenorphine throughout the perioperative period [63・•]. Risks of inadequate pain control must be weighed against risks of relapse and need for buprenorphine re-induction. An individualized approach is recommended with coordination with the buprenorphine prescriber. Logistical considerations such as lack of sublingual or intravenous buprenorphine on hospital formulary for patients who must remain inpatient and maintain a nil per os (NPO) status complicate recommendations further.

\section{Conclusions}

Identifying patients who will benefit from additional resource allocation is vital to improving perioperative outcomes. The preoperative evaluation visit may provide valuable interventions to improve the long-term health of patients by using a comprehensive approach that includes addressing social determinants of health, improving the patient's psychological state and health literacy level and managing patient expectations about postoperative pain and the recovery process. Preoperative interventions aimed at patients at highest risk of poor pain control and opioid use disorder continue to evolve. An individualized, patient-centered approach is emphasized.

\section{Compliance with Ethical Standards}

Conflict of Interest Lisa V. Doan and Jeanna Blitz declare that they have no conflict of interest.

Human and Animal Rights and Informed Consent This article does not contain any studies with human or animal subjects performed by any of the authors.

\section{References}

Papers of particular interest, published recently, have been highlighted as:

- Of importance

-• Of major importance

1. Rachel H. Postoperative pain control. In: Kramer J, editor. . Treasure Island: StatPearls; 2019.

2. Philip BK, Reese PR, Burch SP. The economic impact of opioids on postoperative pain management. J Clin Anesth. 2002;14(5):354 64.

3. Peden CJ, Mythen MG, Vetter TR. Population health management and perioperative medicine: the expanding role of the anesthesiologist. Anesth Analg. 2018;126(2):397-9. https://doi.org/10.1213/ ANE.0000000000002750.

4. Berwick DM, Nolan TW, Whittington J. The triple aim: care, health, and cost. Health Aff (Millwood). 2008;27(3):759-69. https://doi.org/10.1377/hlthaff.27.3.759.
5. Minnella EM, Bousquet-Dion G, Awasthi R, Scheede-Bergdahl C, Carli F. Multimodal prehabilitation improves functional capacity before and after colorectal surgery for cancer: a five-year research experience. Acta Oncol. 2017;56(2):295-300. https://doi.org/10. 1080/0284186X.2016.1268268.

6. Minkowitz HS, Gruschkus SK, Shah M, Raju A. Adverse drug events among patients receiving postsurgical opioids in a large health system: risk factors and outcomes. Am J Health Syst Pharm. 2014;71(18):1556-65. https://doi.org/10.2146/ajhp130031.

7. Shafi S, Collinsworth AW, Copeland LA, Ogola GO, Qiu T, Kouznetsova M, et al. Association of Opioid-Related Adverse Drug Events with Clinical and Cost Outcomes among Surgical Patients in a large integrated health care delivery system. JAMA Surg. 2018;153(8):757-63. https://doi.org/10.1001/jamasurg.2018. 1039.

8. Urman RD, Seger DL, Fiskio JM, Neville BA, Harry EM, Weiner $\mathrm{SG}$, et al. The burden of opioid-related adverse drug events on hospitalized previously opioid-free surgical patients. J Patient Saf. 2019. https://doi.org/10.1097/PTS.0000000000000566.

9. Morris BJ, Sciascia AD, Jacobs CA, Edwards TB. Preoperative opioid use associated with worse outcomes after anatomic shoulder arthroplasty. J Shoulder Elb Surg. 2016;25(4):619-23. https://doi. org/10.1016/j.jse.2015.09.017.

10. Sing DC, Barry JJ, Cheah JW, Vail TP, Hansen EN. Long-acting opioid use independently predicts perioperative complication in Total joint Arthroplasty. J Arthroplast. 2016;31(9 Suppl):170-4 e1. https://doi.org/10.1016/j.arth.2016.02.068.

11. Faour M, Anderson JT, Haas AR, Percy R, Woods ST, Ahn UM, et al. Neck pain, preoperative opioids, and functionality after cervical fusion. Orthopedics. 2017;40(1):25-32. https://doi.org/10.3928/ 01477447-20161013-02.

12. Waljee JF, Cron DC, Steiger RM, Zhong L, Englesbe MJ, Brummett CM. Effect of preoperative opioid exposure on healthcare utilization and expenditures following elective abdominal surgery. Ann Surg. 2017;265(4):715-21. https://doi.org/10. 1097/SLA.0000000000002117.

13. Cron DC, Englesbe MJ, Bolton CJ, Joseph MT, Carrier KL, Moser SE, et al. Preoperative opioid use is independently associated with increased costs and worse outcomes after major abdominal surgery. Ann Surg. 2017;265(4):695-701. https://doi.org/10.1097/SLA. 0000000000001901.

14. Hilliard PE, Waljee J, Moser S, Metz L, Mathis M, Goesling J, et al. Prevalence of preoperative opioid use and characteristics associated with opioid use among patients presenting for surgery. JAMA Surg. 2018. https://doi.org/10.1001/jamasurg.2018.2102.

15. Weick J, Bawa H, Dirschl DR, Luu HH. Preoperative opioid use is associated with higher readmission and revision rates in Total knee and Total hip Arthroplasty. J Bone Joint Surg Am. 2018;100(14): 1171-6. https://doi.org/10.2106/JBJS.17.01414.

16. Blevins Peratikos M, Weeks HL, Pisansky AJB, Yong RJ, Stringer EA. Effect of preoperative opioid use on adverse outcomes, medical spending, and persistent opioid use following elective Total joint Arthroplasty in the United States: a large retrospective cohort study of administrative claims data. Pain Med. 2019. https://doi.org/10. 1093/pm/pnz083.

17. Ben-Ari A, Chansky H, Rozet I. Preoperative opioid use is associated with early revision after Total knee Arthroplasty: a study of male patients treated in the veterans affairs system. J Bone Joint Surg Am. 2017;99(1):1-9. https://doi.org/10.2106/JBJS.16.00167.

18. Dasinger EA, Graham LA, Wahl TS, Richman JS, Baker SJ, Hawn MT, et al. Preoperative opioid use and postoperative pain associated with surgical readmissions. Am J Surg. 2019. https://doi.org/10. 1016/j.amjsurg.2019.02.033.

19. Brummett CM, Waljee JF, Goesling J, Moser S, Lin P, Englesbe MJ, et al. New persistent opioid use after minor and major surgical 
procedures in US adults. JAMA Surg. 2017;152(6):e170504. https://doi.org/10.1001/jamasurg.2017.0504.

20. Sun EC, Darnall BD, Baker LC, Mackey S. Incidence of and risk factors for chronic opioid use among opioid-naive patients in the postoperative period. JAMA Intern Med. 2016;176(9):1286-93. https://doi.org/10.1001/jamainternmed.2016.3298 This retrospective study characterized incidence and risk factors for persistent opioid use after surgery.

21. Gan TJ, Habib AS, Miller TE, White W, Apfelbaum JL. Incidence, patient satisfaction, and perceptions of post-surgical pain: results from a US national survey. Curr Med Res Opin. 2014;30(1):14960. https://doi.org/10.1185/03007995.2013.860019.

22. Gerbershagen HJ, Aduckathil S, van Wijck AJ, Peelen LM, Kalkman CJ, Meissner W. Pain intensity on the first day after surgery: a prospective cohort study comparing 179 surgical procedures. Anesthesiology. 2013;118(4):934-44. https://doi.org/10. 1097/ALN.0b013e31828866b3.

23. Gerbershagen HJ, Pogatzki-Zahn E, Aduckathil S, Peelen LM, Kappen TH, van Wijck AJ, et al. Procedure-specific risk factor analysis for the development of severe postoperative pain. Anesthesiology. 2014;120(5):1237-45. https://doi.org/10.1097/ ALN.0000000000000108.

24. Kalkman CJ, Visser K, Moen J, Bonsel GJ, Grobbee DE, Moons KG. Preoperative prediction of severe postoperative pain. Pain. 2003;105(3):415-23. https://doi.org/10.1016/s0304-3959(03) 00252-5

25. Tighe PJ, Le-Wendling LT, Patel A, Zou B, Fillingim RB. Clinically derived early postoperative pain trajectories differ by age, sex, and type of surgery. Pain. 2015;156(4):609-17. https://doi.org/10.1097/ 01.j.pain.0000460352.07836.0d.

26. Hah JM, Cramer E, Hilmoe H, Schmidt P, McCue R, Trafton J, et al. Factors associated with acute pain estimation, postoperative pain resolution, opioid cessation, and recovery: secondary analysis of a randomized clinical trial. JAMA Netw Open. 2019;2(3): e190168. https://doi.org/10.1001/jamanetworkopen.2019.0168.

27. Patanwala AE, Jarzyna DL, Miller MD, Erstad BL. Comparison of opioid requirements and analgesic response in opioid-tolerant versus opioid-naive patients after total knee arthroplasty. Pharmacotherapy. 2008;28(12):1453-60. https://doi.org/10.1592/ phco.28.12.1453.

28. Chapman CR, Davis J, Donaldson GW, Naylor J, Winchester D. Postoperative pain trajectories in chronic pain patients undergoing surgery: the effects of chronic opioid pharmacotherapy on acute pain. J Pain. 2011;12(12):1240-6. https://doi.org/10.1016/j.jpain. 2011.07.005.

29. Aasvang EK, Lunn TH, Hansen TB, Kristensen PW, Solgaard S, Kehlet H. Chronic pre-operative opioid use and acute pain after fast-track total knee arthroplasty. Acta Anaesthesiol Scand. 2016;60(4):529-36. https://doi.org/10.1111/aas.12667.

30. Dunn LK, Durieux ME, Fernandez LG, Tsang S, Smith-Straesser $\mathrm{EE}$, Jhaveri HF, et al. Influence of catastrophizing, anxiety, and depression on in-hospital opioid consumption, pain, and quality of recovery after adult spine surgery. J Neurosurg Spine. 2018;28(1): 119-26. https://doi.org/10.3171/2017.5.SPINE1734.

31. Schreiber KL, Zinboonyahgoon N, Xu X, Spivey T, King T, Dominici L, et al. Preoperative psychosocial and psychophysical phenotypes as predictors of acute pain outcomes after breast surgery. J Pain. 2019;20(5):540-56. https://doi.org/10.1016/j.jpain. 2018.11.004.

32. Sipila RM, Haasio L, Meretoja TJ, Ripatti S, Estlander AM, Kalso EA. Does expecting more pain make it more intense? Factors associated with the first week pain trajectories after breast cancer surgery. Pain. 2017;158(5):922-30. https://doi.org/10.1097/j.pain. 0000000000000859

33. Bayman EO, Parekh KR, Keech J, Larson N, Vander Weg M, Brennan TJ. Preoperative patient expectations of postoperative pain are associated with moderate to severe acute pain after VATS. Pain Med. 2019;20(3):543-54. https://doi.org/10.1093/pm/pny096.

34. Simanski CJ, Althaus A, Hoederath S, Kreutz KW, Hoederath P, Lefering $\mathrm{R}$, et al. Incidence of chronic postsurgical pain (CPSP) after general surgery. Pain Med. 2014;15(7):1222-9. https://doi. org/10.1111/pme.12434.

35. Fletcher D, Stamer UM, Pogatzki-Zahn E, Zaslansky R, Tanase NV, Perruchoud C, et al. Chronic postsurgical pain in Europe: an observational study. Eur J Anaesthesiol. 2015;32(10):725-34. https://doi. org/10.1097/EJA.0000000000000319.

36. Kehlet H, Jensen TS, Woolf CJ. Persistent postsurgical pain: risk factors and prevention. Lancet. 2006;367(9522):1618-25. https:// doi.org/10.1016/S0140-6736(06)68700-X.

37. Chidambaran V, Gang Y, Pilipenko V, Ashton M, Ding L. Systematic review and meta-analysis of genetic risk of developing chronic postsurgical pain. J Pain. 2019. https://doi.org/10.1016/j. jpain.2019.05.008.

38. Althaus A, Hinrichs-Rocker A, Chapman R, Arranz Becker O, Lefering R, Simanski C, et al. Development of a risk index for the prediction of chronic post-surgical pain. Eur J Pain. 2012;16(6):901-10. https://doi.org/10.1002/j.1532-2149.2011. 00090.x.

39. Masselin-Dubois A, Attal N, Fletcher D, Jayr C, Albi A, Fermanian $\mathrm{J}$, et al. Are psychological predictors of chronic postsurgical pain dependent on the surgical model? A comparison of total knee arthroplasty and breast surgery for cancer. J Pain. 2013;14(8): 854-64. https://doi.org/10.1016/j.jpain.2013.02.013.

40. Lewis GN, Rice DA, McNair PJ, Kluger M. Predictors of persistent pain after total knee arthroplasty: a systematic review and metaanalysis. Br J Anaesth. 2015;114(4):551-61. https://doi.org/10. 1093/bja/aeu441.

41. Rasouli MR, Menendez ME, Sayadipour A, Purtill JJ, Parvizi J. Direct cost and complications associated with Total joint Arthroplasty in patients with preoperative anxiety and depression. J Arthroplast. 2016;31(2):533-6. https://doi.org/10.1016/j.arth. 2015.09.015.

42. Menendez ME, Neuhaus V, Bot AG, Ring D, Cha TD. Psychiatric disorders and major spine surgery: epidemiology and perioperative outcomes. Spine (Phila Pa 1976). 2014;39(2):E111-22. https://doi. org/10.1097/BRS.0000000000000064.

43. Zemła AJ, Nowicka-Sauer K, Jarmoszewicz K, Wera K, Batkiewicz S, Pietrzykowska M. Measures of preoperative anxiety. Anaesthesiol Intensive Ther. 2019;51(1):64-9. https://doi.org/10. 5603/AIT.2019.0013.

44. Zigmond AS, Snaith RP. The hospital anxiety and depression scale. Acta Psychiatr Scand. 1983;67(6):361-70. https://doi.org/10.1111/ j.1600-0447.1983.tb09716.x.

45. Sullivan M. The Pain Catastrophizing Scale. User manual. Montreal: McGill University; 2009.

46. Darnall BD, Sturgeon JA, Cook KF, Taub CJ, Roy A, Burns JW, et al. Development and validation of a daily Pain Catastrophizing Scale. J Pain. 2017;18(9):1139-49. https://doi.org/10.1016/j.jpain. 2017.05.003.

47. Webster LR. Risk factors for opioid-use disorder and overdose. Anesth Analg. 2017;125(5):1741-8. https://doi.org/10.1213/ANE. 0000000000002496.

48. Akbik H, Butler SF, Budman SH, Fernandez K, Katz NP, Jamison RN. Validation and clinical application of the screener and opioid assessment for patients with pain (SOAPP). J Pain Symptom Manag. 2006;32(3):287-93. https://doi.org/10.1016/j. jpainsymman.2006.03.010.

49. Stessel B, Fiddelers AA, Marcus MA, van Kuijk SM, Joosten EA, Peters ML, et al. External validation and modification of a predictive model for acute postsurgical pain at home after day surgery. Clin J Pain. 2017;33(5):405-13. https://doi.org/10.1097/AJP. 0000000000000413 . 
50. Tighe PJ, Harle CA, Hurley RW, Aytug H, Boezaart AP, Fillingim RB. Teaching a machine to feel postoperative pain: combining high-dimensional clinical data with machine learning algorithms to forecast acute postoperative pain. Pain Med. 2015;16(7):1386401. https://doi.org/10.1111/pme.12713.

51. Powell R, Scott NW, Manyande A, Bruce J, Vogele C, Byrne-Davis LM, et al. Psychological preparation and postoperative outcomes for adults undergoing surgery under general anaesthesia. Cochrane Database Syst Rev. 2016;5:CD008646. https://doi.org/10.1002/ 14651858.CD008646.pub2.

52. Rolving N, Nielsen CV, Christensen FB, Holm R, Bunger CE, Oestergaard LG. Preoperative cognitive-behavioural intervention improves in-hospital mobilisation and analgesic use for lumbar spinal fusion patients. BMC Musculoskelet Disord. 2016;17:217. https://doi.org/10.1186/s12891-016-1078-8.

53. Yi JL, Porucznik CA, Gren LH, Guan J, Joyce E, Brodke DS, et al. The impact of preoperative mindfulness-based stress reduction on postoperative patient-reported pain, disability, quality of life, and prescription opioid use in lumbar spine degenerative disease: a pilot study. World Neurosurg. 2018. https://doi.org/10.1016/j.wneu. 2018.09.223.

54. Aronson S, Westover J, Guinn N, Setji T, Wischmeyer P, Gulur P, et al. A perioperative medicine model for population health: an integrated approach for an evolving clinical science. Anesth Analg. 2018;126(2):682-90. https://doi.org/10.1213/ANE. 0000000000002606.

55. Bair E, Ohrbach R, Fillingim RB, Greenspan JD, Dubner R, Diatchenko L, et al. Multivariable modeling of phenotypic risk factors for first-onset TMD: the OPPERA prospective cohort study. J Pain. 2013;14(12 Suppl):T102-15. https://doi.org/10.1016/j. jpain.2013.09.003.

56.• Edwards DA, Hedrick TL, Jayaram J, Argoff C, Gulur P, Holubar SD, et al. American Society for Enhanced Recovery and Perioperative Quality Initiative Joint Consensus Statement on perioperative Management of Patients on preoperative opioid therapy. Anesth Analg. 2019;129(2):553-66. https://doi.org/10.1213/ANE. 0000000000004018 American Society for Enhanced Recovery and Perioperative Quality Initiative publication on perioperative management of patients on preoperative opioids.
57. Nguyen LC, Sing DC, Bozic KJ. Preoperative reduction of opioid use before Total joint Arthroplasty. J Arthroplast. 2016;31(9 Suppl): 282-7. https://doi.org/10.1016/j.arth.2016.01.068.

58. Ward EN, Quaye AN, Wilens TE. Opioid use disorders: perioperative Management of a Special Population. Anesth Analg. 2018;127(2):539-47. https://doi.org/10.1213/ANE. 0000000000003477.

59. Curatolo C, Trinh M. Challenges in the perioperative management of the patient receiving extended-release naltrexone. A A Case Rep. 2014;3(11):142-4. https://doi.org/10.1213/XAA. 0000000000000069.

60. Israel JS, Poore SO. The clinical conundrum of perioperative pain management in patients with opioid dependence: lessons from two cases. Plast Reconstr Surg. 2013;131(4):657e-8e. https://doi.org/ 10.1097/PRS.0b013e31828277bd.

61. Anderson TA, Quaye ANA, Ward EN, Wilens TE, Hilliard PE, Brummett CM. To stop or not, that is the question: acute pain Management for the Patient on chronic buprenorphine. Anesthesiology. 2017;126(6):1180-6. https://doi.org/10.1097/ ALN.0000000000001633.

62. Lembke A, Ottestad E, Schmiesing C. Patients maintained on buprenorphine for opioid use disorder should continue buprenorphine through the perioperative period. Pain Med. 2019;20(3):425-8. https://doi.org/10.1093/pm/pny019.

63.• Goel A, Azargive S, Weissman JS, Shanthanna H, Hanlon JG, Samman B, et al. Perioperative Pain and Addiction Interdisciplinary Network (PAIN) clinical practice advisory for perioperative management of buprenorphine: results of a modified Delphi process. Br J Anaesth. 2019;123(2):e333-e42. https://doi. org/10.1016/j.bja.2019.03.044 The most recent advisory on perioperative management of buprenorphine.

64. Goel A, Azargive S, Lamba W, Bordman J, Englesakis M, Srikandarajah S, et al. The perioperative patient on buprenorphine: a systematic review of perioperative management strategies and patient outcomes. Can J Anaesth. 2019;66(2):201-17. https://doi. org/10.1007/s12630-018-1255-3.

Publisher's Note Springer Nature remains neutral with regard to jurisdictional claims in published maps and institutional affiliations. 